\title{
WARD ROUND PRACTICE OF NURSES AND MIDWIFES AT HANOI OBSTETRICS AND GYNECOLOGY HOSPITAL IN 2021
}

\author{
Nguyen Thi Bich Hanh ${ }^{1}$, Nguyen Duy Anh ${ }^{1}$ \\ ${ }^{1}$ Hanoi obstetrics and gynecology Hospital
}

\begin{abstract}
Objective: To describe the ward round practice of nurses and midwifes at Hanoi Obstetrics and Gynecology Hospital in 2021. Method: A cross-sectional descriptive research, combining quantitative and qualitative research was conducted on 113 nurses, midwives and 08 managers in 04 clinical ward: A3, A4, D4, D5 at Hanoi Obstetrics and gynecology hospital. Results: Most of the ward round practice contents were done well. In particular, $100 \%$ of nurses and midwives worn fully medical clothes as prescribed; following by the provided adequate advice on prevention and health improvement for patients (89.4\%). However, only $17.7 \%$ of nurses and midwives disseminated fully about patient obligations; $22.1 \%$ of them greeted the patient and introduced themselves fully to the patients; $30.1 \%$ provided fully information about rules of ward and patient rights; $34.5 \%$ gave fully the guideline for postpartum mothers. Conclusion: The percentage of nurses and midwives in Hanoi Obstetrics and Gynecology Hospital who perform the routine ward round quite well is over $80 \%$.
\end{abstract}

Keywords: Ward round, nurse, midwifery, Hanoi obstetrics and gynecology Hospital

\section{INTRODUCTION}

Routine ward round is a regular daily task of nurses and midwives. This is one of the effectively physical and mental care for early detection of the patients' abnormal symptoms. This is a patient care process that takes up more time than other professional processes, requiring nurses and midwives to have good skills, knowledge and attitude [1].

According to literature review, we found that there is a lack of studies about routine ward round of nurses and midwives; studies about the advantages and disadvantages of performing ward round. Hanoi Obstetrics and Gynecology Hospital has 32 wards which is a Class I specialized hospital was managed by Hanoi Department of Health. The assessment of the nursing care process in general, the assessment of knowledge, attitude and practice of ward round process in particular is necessary, in order to find out the current status, advantages and disadvantages in the ward round process. Thereby finding solutions to improve the capacity of nurses and midwives, and changing management methods in order to better perform ward round activities. For that reason, we conducted the study with the objective: "To describe the ward round practice of nurses and midwifes at Hanoi Obstetrics and Gynecology Hospital in 2021".
Cor. author: Nguyen Thi Bich Hanh

Address: Hanoi Obstetrics and Gynecology Hospital

Email: violet3181974@gmail.com
Received: Dec 24, 2021

Accepted: Feb 24, 2022

Published: Feb 25, 2022 


\section{SUBJECTS AND METHODS}

\subsection{Subjects, setting and research period}

\subsubsection{Subjects}

- Quantitative research:

Research subjects are nurses and midwives who participated in routine ward round at 04 wards: A3, A4, D4, D5.

- Qualitative research:

Research subjects are managers, nurses and midwives at 4 clinical wards: A3, A4, D4, D5.

\subsubsection{Setting and research period}

The study was conducted at 04 clinical wards: A3, A4, D4, D5 of Hanoi Obstetrics and Gynecology Hospital from December 2020 to March 2021.

\subsection{Methods}

2.2.1. Research design: Crosssectional descriptive study, combining quantitative and qualitative research.

\subsubsection{Sample size and sampling method}

* Quantitative research:

- Sample size: Including 113 nurses and midwives participated in routine ward round at 04 wards: A3, A4, D4, D5.

- Sampling method: Collected all nurses and midwives that met the criteria using the convenient sampling method.

* Qualitative research:

- Two in-depth interviews: choose the Deputy Director and the Chief Nursing Officer of the hospital.

- Five group discussions:

+01 group discussions with the subjects are the head doctors and head nurses at 04 wards: A3, A4, D4, D5 (8 people).

+ 04 group discussions with the subjects are nurses and midwives at 04 wards: A3, A4, D4, D5; Each ward is a group discussion with 4 people.

\subsubsection{Research instruments}

The research instruments were developed base on Hanoi Obstetrics and Gynecology Hospital's regulations on routine ward round of nurses and midwives (Decision No.1258 QĐ/PSTCCB dated 03/11/2016 of the Director of Hanoi Obstetrics and Gynecology Hospital about "Regulations on Nursing work"). The routine ward round procedure was based on Circular 07/2011/TT - BYT dated January 26, 2011 guiding the nursing care for patients in the hospital.

The research instruments were including:

- Practicing in routine ward round of nurses and midwives

- Wearing medical clothes of the nurses and midwives.

- Greeting the patient, and introduce themselves to the patients of the nurses and midwives.

- Providing information about rules of ward and patient rights of nurses and midwives.

- Disseminating about patient obligations of nurses and midwives.

- Providing adequate advice on prevention and health improvement for patients of nurses and midwives.

- Giving the guideline for postpartum mothers of nurses and midwives. 


\subsubsection{Data collection}

- The researcher and 04 investigators from the Nursing Department of Hanoi Obstetrics and Gynecology Hospital observed and interviewed the research subjects by using questionnaire.

+ Each investigator supervised and was the chairperson of each group discussions at their ward to collect data.

+ The researcher in charged to collect data by in-depth interview.

\subsubsection{Data analysis}

- Quantitative data were cleaned then entered using Epi Data 3.1 software. The data were synthesized by using SPSS 16.0 software. Descriptive statistical including mean, percentage, and standard deviation were used to describe information

- Qualitative data were coded by topic and quoted typical opinions in the presentation of research results.

\subsubsection{Ethics consideration}

- The study was approved by the Ethical Review Board of Namdinh University of Nursing and had agreement from Hanoi Obstetrics and Gynecology Hospital. An informed consent was obtained to ensure that the subjects voluntarily participated in this study. Participants have the right to withdraw from the study at any time

- The responses would be kept strictly confidential, and their identity will not be revealed, only use for research purposes

\section{RESULTS}

Table 1. Wearing medical clothes $(n=113)$

\begin{tabular}{|lcc|}
\hline \multicolumn{1}{|c|}{ Contents } & \multicolumn{2}{c|}{$\begin{array}{c}\text { Perform of nurses } \\
\text { and midwives } \\
\text { Frequency }\end{array}$} \\
\hline Pear medical clothes when visiting and taking care of patients & 113 & 100 \\
\hline Medical clothes were neatly and cleanly, and button up the shirt neatly & 113 & 100 \\
\hline Wear a card on chest, clearly print name and position & 113 & 100 \\
\hline FULLY PERFORM & 113 & 100 \\
\hline
\end{tabular}

The nurses and midwives of the hospital has performed very well in wearing medical clothes with $100 \%$ fulfilling all the criteria.

The results of the qualitative research showed that all nurses and midwives worn fully medical clothes as prescribed while going to the ward because: "According to Circular 45 of the Ministry of Health 2014, the regulations on dress code of nurses and midwives must be changed. In two years, the old medical clothes model will be changed to the new model with blue border. The hospital has provided to the staff with new clothes. A few years ago, some nurses and midwives regretted that they still wore old clothes that were no longer up to standards. However, after nearly 8 years of implementation, all nurses and midwives have enough new clothes. Moreover, the annual hospital quality assessment is also actively implemented, nurses and midwives always comply with regulations" (In-depth interview - Leader 02). 
Table 2. Greeting the patient, and introduce themselves to the patients $(n=113)$

\begin{tabular}{|c|c|c|}
\hline \multirow{2}{*}{ Contents } & \multicolumn{2}{|c|}{ Perform of nurses and midwives } \\
\hline & Frequency & Percent \\
\hline Being on time & 113 & 100 \\
\hline Greeting the patients upon arrival & 112 & 99.1 \\
\hline Introducing name and position to the patients & 102 & 90.3 \\
\hline Asking about the patient's general condition & 31 & 27.2 \\
\hline Instructing patients to follow hospital rules & 58 & 51.3 \\
\hline Greeting the patients after leaving the ward & 112 & 99.1 \\
\hline FULLY PERFORM & 25 & 22.1 \\
\hline
\end{tabular}

Nurses and midwives performed ward round duties such as arriving on time accounted for the highest percentage with $100 \%$, followed by greeting patients upon arrival and after leaving the ward accounted for $99.1 \%$, followed by come to introduce to NB about the name and title with the rate of $90.3 \%$. Meanwhile, asking about the patient's general condition was the lowest with $27.2 \%$ of nurses and midwives.

One of leaders told that: "Young nurses and midwives often do not have much experience with the disease, so they are not autonomy in asking about the patient's status, considering the inquiry is the responsibility of the doctor during the ward round" (In-depth interview - Leader 01).

"On the days when the hospital is crowded, nurses and midwives performed ward round very quickly to do other things in time. So that it made ward round less efficient, sometimes they didn't even have time to introduce their name, title, ask about the patient's situation" (Group discussion - Leader 04).

Table 3. Providing information about rules of ward and patient rights $(n=113)$

\begin{tabular}{|lcc|}
\hline \multicolumn{1}{|c}{ Contents } & $\begin{array}{c}\text { Perform of nurses and midwives } \\
\text { Frequency }\end{array}$ & Percent \\
\hline $\begin{array}{l}\text { Disseminating the patient's right to medical examination } \\
\text { and care. }\end{array}$ & 77 & 68.1 \\
\hline $\begin{array}{l}\text { Disseminating the patient's right to be served food according } \\
\text { to the pathological regimen. }\end{array}$ & 111 & 72.6 \\
\hline $\begin{array}{l}\text { Disseminating for patients to use hospital equipment } \\
\text { (clothes, blankets, mats) }\end{array}$ & 112 & 98.2 \\
\hline $\begin{array}{l}\text { Disseminating for patients to change clothes on a daily/ } \\
\text { scheduled }\end{array}$ & 52 & 46.1 \\
\hline Explanting to patients about their illness & 83 & 73.5 \\
\hline $\begin{array}{l}\text { Disseminating to patients that the drug will be disclosed } \\
\text { when used }\end{array}$ & & 46.0 \\
\hline
\end{tabular}




\begin{tabular}{|c|c|c|}
\hline \multirow{2}{*}{ Contents } & \multicolumn{2}{|c|}{ Perform of nurses and midwives } \\
\hline & Frequency & Percent \\
\hline Explaining to patients how to rest & 58 & 51.3 \\
\hline $\begin{array}{l}\text { Instructing the patient and the patient's family to give } \\
\text { comments on the responsibility and service attitude of } \\
\text { healthcare workers }\end{array}$ & 59 & 52.2 \\
\hline Guiding the patient's family how to visit the patients & 85 & 75.2 \\
\hline FULLY PERFORM & 34 & 30.1 \\
\hline
\end{tabular}

Nurses and midwives who fully provided to patients that they were allowed to change their clothes daily (99.1\%) and use hospital tools $(98.2 \%)$. However, the explanation of how to live and rest accounted for only $51.3 \%$.

Table 4. Disseminating about patient obligations $(n=113)$

\begin{tabular}{|c|c|c|}
\hline \multirow{2}{*}{ Contents } & \multicolumn{2}{|c|}{ Perform of nurses and midwives } \\
\hline & Frequency & Percent \\
\hline $\begin{array}{l}\text { Disseminate and instruct patients who are obligated to } \\
\text { fully comply with the doctor's orders: type of drug, dosage, } \\
\text { and duration of use. }\end{array}$ & 79 & 69.9 \\
\hline Fully instruct and ask patients to follow hospital rules & 81 & 71.7 \\
\hline $\begin{array}{l}\text { Instructing and requesting patients to pay hospital fees } \\
\text { and administrative procedures for admission/discharge }\end{array}$ & 112 & 99.1 \\
\hline Encourage patients to unite and help each other & 26 & 23.0 \\
\hline FULLY PERFORM & 20 & 17.7 \\
\hline
\end{tabular}

The nurses fully followed the doctor's orders: the type of drug, the dose, and the duration of use accounted for $69.9 \%$; Fully instruct and ask patients to follow hospital rules $71.7 \%$; Instructing and requesting patients to pay for hospital fees and administrative procedures for admission/discharge accounted for $99.1 \%$; Encouraging patients to help each other accounts for $23.0 \%$.

According to qualitative research, nurses and midwives felt that the process of ward round too long and took too much time, so they automatically cut off the steps. "When we did the ward round, we found that speaking in full detail, it took a bit of time, so many times we spoke quickly and short, sometimes lacking in content" (Group discussion - nurses/ midwives 10).

The leader of hospital also found a gap in management: "The nurses and midwives had knowledge but only works hard to nursing care technical, ward round must talk and give advice. However, nurses and midwives are still lack of counseling skills. So that, they need more training on this issue" (In-depth interview - Leader 01). 
Table 5. Providing adequate advice on prevention and health improvement for patients $(n=113)$

\begin{tabular}{|lcc|}
\hline \multicolumn{1}{|c}{ Contents } & Perform of nurses and midwives \\
& Frequency & Percent \\
\hline Guiding the dietary & 102 & 90.3 \\
\hline Instructing how to exercise, life style and resting & 101 & 89.4 \\
\hline Instructing how to personal hygiene & 102 & 90.3 \\
\hline \multicolumn{1}{|c|}{ FULLY PERFORM } & 101 & 89.4 \\
\hline
\end{tabular}

Nurses and midwives gave good advice on prevention and health improvement for patients with all 3 criteria reaching approximately $90 \%$.

According to the qualitative research, the Nurses and midwives replied, "Through the practice routine ward round, I like the content of health education counseling the most because the patients pay a lot of attention and ask a lot of questions. I felt that I provided very good service for the patient" (Group discussion - nurses/midwives 02).

Table 6. Giving the guideline for postpartum mothers $(n=113)$

\begin{tabular}{|lcc|}
\hline \multicolumn{1}{|c}{ Contents } & \multicolumn{2}{c|}{ Perform of nurses and midwives } \\
& Frequency & Percent \\
\hline Guiding breastfeeding & 80 & 70.8 \\
\hline Instructing newborn care & 54 & 48.7 \\
\hline Instructing how to monitor abnormal signs & 68 & 60.2 \\
\hline Troubleshooting & 106 & 93.8 \\
\hline $\begin{array}{l}\text { Instructing the patient to report the doctor when there is } \\
\text { something abnormal }\end{array}$ & 107 & 94.7 \\
\hline \multicolumn{1}{|c}{ FULLY PERFORM } & 39 & 34.5 \\
\hline
\end{tabular}

Nurses and midwives who guided breastfeeding accounted for $70.8 \%$. After this research we expected this rate will be much higher, this is also a reminder for management to strengthen supervision as well as training of nurses and midwives in counseling breastfeeding. Nurses and midwives instructing newborn care accounted for $48.7 \%$; Nurses and midwives instructing to monitor abnormal signs accounted for $60.2 \%$; answering questions accounted for $93.8 \%$; Instructing the patient to report to the doctor when there is something abnormal accounted for $94.7 \%$.

Qualitative research results: "In the postpartum ward, it is indispensable to provide postpartum guidance for pregnant women. Nurses and midwives in the ward are reminded and regularly monitored about this criterion" (Group discussion - Leader 04). However, there are still certain difficulties: "When the mother was tired and didn't listen, we forgot to ask after the instructions, and had to give instructions again, which took a lot of time!" (Group discussion - nurses/midwives 03). 


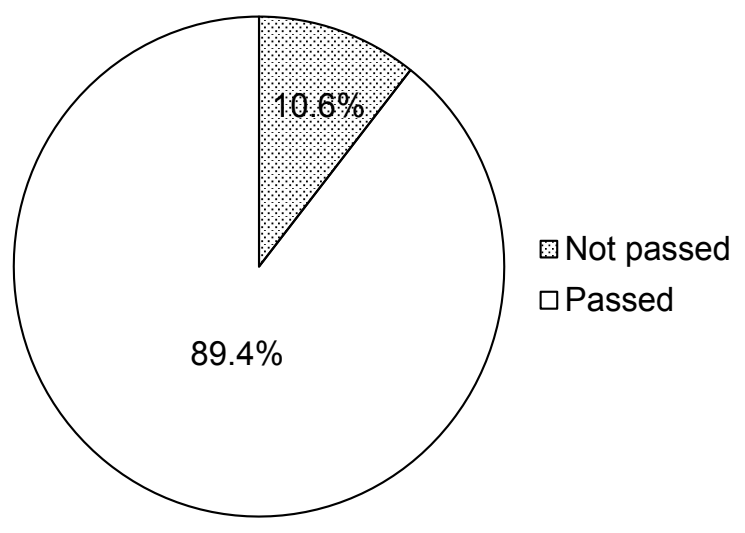

Figure 3.1. Practicing in routine ward round of nurses and midwives

The rate of nurses and midwives reaching more than $80 \%$ of the contents of ward round was $89.4 \%$. From this result, it also shows the effectiveness of the ward round of nurses and midwives at the hospital, which contributes to $41.6 \%$ of patients feel more secure when having the procedure; 54.9 patients feel very good because they know how to take care of themselves and adhere to the self-disciplined treatment regimen and $80.5 \%$ of patients are more friendly and cooperative when nurses and midwives take care of them.

\section{DISCUSSION}

\subsection{Wearing medical clothes of the nurses and midwives}

Medical clothes are an important factor in each healthcare worker in general and the nurses and midwives while doing the ward round in particular. Medical clothes are the first external image to create trust and sympathy of the patient for nurses and midwives. When the healthcare worker wear correctly medical clothes contribute to building professionalism and helps patients trust in treatment. From that, it can be said that clothing is a part of service quality [2].

The results showed that nurses and midwives have performed very well in terms of costumes with $100 \%$ fulfilling all the criteria. This finding is higher than the finding of Pham Thi Xuyen at Ha Dong General Hospital, in which more than $98 \%$ of nurses regularly wear clean and neat medical clothes and wear a staff sign in accordance with regulations [3]. This difference can be explained that after 8 years of implementing Circular 45 , the hospital has provided enough medical clothes for nurses and midwives in both quantity and quality. The Nurses and midwives had enough medical clothes to spare in case of urgent need, so there is no need to reuse the old clothes, the quality is not guaranteed.

4.2. Greeting the patient, and introduce themselves to the patients of the nurses and midwives

Fully implementing the steps in the ward round procedure is strictly comply with the principles of communicating with patients and providing adequate information on hospital regulations and health education for patients. Following the correct procedure helps patients not only update necessary information but also feel that the nurses and midwives are respectful and friendly.

Besides, Nurses and midwives performing ward round duties such as arriving on time accounted for the highest percentage with $100 \%$, followed by greeting patients upon arrival and after leaving the ward accounting for $99.1 \%$, followed by come to introduce to patients about the name and position with the rate of $90.3 \%$. Meanwhile, asking about the patient's general condition was the lowest with $27.2 \%$ of nurses and midwives. 
The finding showed that: "Young nurses and midwives often do not have much experience with the disease, so they are not autonomy in asking about the patient's status, considering the inquiry is the responsibility of the doctor during the ward round" (In-depth interview - Leader $01)$. "On the days when the hospital is crowded, nurses and midwives performed ward round very quickly to do other things in time. So that it made ward round less efficient, sometimes they didn't even have time to introduce their name, title, ask about the patient's situation" (Group discussion Leader 04). Interview results have reflected the reality of the current situation of hospital overcrowding, the work of nurses a lot leading to a situation of "superficial" with patients. In fact, the training of skills for nurses and midwives can be increased by simple training method. Do Manh Hung's research showed that the percentage of nurses offering to sit down and ask their name increased from $77.6 \%$ to $94.8 \%$, Introduce yourself, state the reason for contact with the patient increased from $34 \%$ to $81.7 \%$ [4]. Our research results are similar to the research results of Pham Thi Xuyen when interviewing about the nurses' ward round experience [3]. Therefore, it is necessary to training about ward round for nurses and midwives to improve the quality of patient care services at Hanoi Obstetrics and Gynecology Hospital.

\subsection{Providing information about rules of ward and patient rights of nurses and midwives}

Patients need to know their rights. thereby helping patients to take the initiative in asking for reasonable care needs as well as being proactive in improving their own health. Our study found that most nurses and midwives fully provided information to patients about changing clothes every day $(99.1 \%)$ and using hospital tools (98.2\%). However, the explanation of how to live and rest accounted for only $51.3 \%$.

According to Decision 2151/BYT on renewing the style and attitude of medical staff towards patient satisfaction, hospital had some changing contents such as Inbox for suggestions, maintaining a hotline online with hospital leaders to encourage patients to make comments. However, the hospital still needs to strengthen the work of directly instructing patients during the process of routine ward round [5].

In order to improve the hospital's quality, regular reception of suggestions and feedback is essential. According to Do Manh Hung, comments play an important role in changing the attitudes and service ethics of nurses [4]. However, the rate of research on guiding patients to give comments to the hospital is still low, so from the perspective of management of Hanoi Obstetrics and Gynecology Hospital, it is necessary to promote the work of guiding and encouraging patients to give comments.

\subsection{Disseminating about patient obligations of nurses and midwives}

Information about the patient's obligations is really very important, contributing to ensuring that the patient follows the rules, security and order and the hospital fees are fully paid. The results of Table 4 showed that the nurses fully followed the doctor's orders: the type of drug, the dose, and the duration of use accounted for $69.9 \%$; Fully instruct and ask patients to follow hospital rules $71.7 \%$; Instructing and requesting patients to pay for hospital fees and administrative procedures for 
admission/discharge accounted for $99.1 \%$; Encouraging patients to help each other accounts for $23.0 \%$.

According to qualitative research, nurses and midwives felt that the process of ward round too long and took too much time, so they automatically cut off the steps. "When we did the ward round, we found that speaking in full detail, it took a bit of time, so many times we spoke quickly and short, sometimes lacking in content" (Group discussion - nurses/midwives 10). The leader of hospital also found a gap in management: "The nurses and midwives had knowledge but only works hard to nursing care technical, ward round must talk and give advice. However, nurses and midwives are still lack of counseling skills. So that, they need more training on this issue" (In-depth interview - Leader 01). Base on the results, we identified that it is very necessary to improve the professional qualifications of nurses. This result is similar to the results of Pham Thi Xuyen when conducted at Ha Dong General Hospital. Comparing to the research results of Hoang Tien Thang at Son Tay General Hospital in 2010 showed that nurses guide the patient's rights and obligations while hospitalized accounted for 93\% [6]. According to Pham Thi Xuyen, the nurse disseminating the compliance with regulations in medical examination and treatment accounted for $69.3 \%$, the nurse disseminating information about payment of expenses in medical examination and treatment accounted for $70 \%$ [3].

\subsection{Providing adequate advice on prevention and health improvement for patients of nurses and midwives}

Nurses and midwives who provide counseling to prevent and improve the health of patients play an important role of nurses. Counseling helps patients take the initiative to take care of their own health through hygiene, living, and rest. Nurses and midwives gave good advice on prevention and health improvement for patients with all 3 criteria reaching approximately $90 \%$. This finding is higher than some studies. Study of Pham Thi Xuyen at Ha Dong General Hospital showed that $61.3 \%$ of nurses explained to patients about the disease and how to take care of themselves, $64.7 \%$ nurses instructed patients how to eat healthy, $52 \%$ of nurses instructed patients how to rest and exercise in accordance with their health, $29.3 \%$ of nurses instructed patients on personal hygiene, $54 \%$ of nurses instructed patients on how to detect abnormal happenings and incidents [3]. Study of Ha Kim Phuong at the Nam Dinh Provincial Psychiatric Hospital showed that $83.4 \%$ of nurses provided dietary guidelines [7].

According to the qualitative research, the Nurses and midwives replied, "Through the practice routine ward round, I like the content of health education counseling the most because the patients pay a lot of attention and ask a lot of questions. I felt that I provided very good service for the patient" (Group discussion - nurses/midwives 02). However, it should be noted that each patient, each hospital has the content of health promotion completely different. The content of instructions for mothers after giving birth is content including newborn care, detecting abnormal signs in mothers and babies. This content is actually part of the health promotion content.

\subsection{Giving the guideline for postpartum mothers of nurses and midwives}

As a friendly hospital, Hanoi Obstetrics and Gynecology Hospital always puts 
breast-feeding criteria first, thoroughly applying Decree 21 on the use of nutritional products for children. The results showed that $70.8 \%$ of nurses and midwives guided breastfeeding for mothers. After this research we expected this rate will be much higher, this is also a reminder for management to strengthen supervision as well as training of nurses and midwives in counseling breastfeeding. Nurses and midwives instructing newborn care accounted for 48.7\%; Nurses and midwives instructing to monitor abnormal signs accounted for $60.2 \%$; answering questions accounted for $93.8 \%$; Instructing the patient to report to the doctor when there is something abnormal accounted for $94.7 \%$. The findings are higher than the results of $\mathrm{Ha}$ Thi Kim Phuong's research on nursing counseling and training. This is very important advice contents to help patients have self-care knowledge, reduce the rate of postpartum bleeding at the hospital. In fact, these are important contents to help postpartum mothers take care of themselves and their babies. The overall rating is only $34.5 \%$. It means that it is necessary to further strengthen the guidance of postpartum mothers on child rearing.

The results of the qualitative study show that: "In the postpartum ward, it is indispensable to provide postpartum guidance for pregnant women. Nurses and midwives in the ward are reminded and regularly monitored about this criterion" (Group discussion - Leader 04). However, there are still certain difficulties: "When the mother was tired and didn't listen, we forgot to ask after the instructions, and had to give instructions again, which took a lot of time!" (Group discussion - nurses/midwives 03).

\subsection{Practicing in routine ward round of nurses and midwives}

The rate of nurses and midwives reaching more than $80 \%$ of the contents of ward round was $89.4 \%$. From this result, it also shows the effectiveness of the ward round of nurses and midwives at the hospital, which contributes to $41.6 \%$ of patients feel more secure when having the procedure; 54.9 patients feel very good because they know how to take care of themselves and adhere to the self-disciplined treatment regimen and $80.5 \%$ of patients are more friendly and cooperative when nurses and midwives take care of them.

\section{CONCLUSION}

Through the study of 113 nurses/ midwives and 08 leaders participating in routine ward round, we found that the percentage of nurses/midwives in Hanoi Obstetrics and Gynecology Hospital who performed the routine procedure quite well accounted for over $80 \%$. To improve the quality of hospitals, improving professional capacity and skills for nurses is an urgent and practical need in the current situation.

\section{REFERENCES}

1. Hanoi Obstetrics and Gynecology Hospital (2016), Regulations on routine bedside assessment of nurses and students, Decision No: 1258 QD/PS-TCCB, dated November 3, 2016 of the Director of Hanoi Obstetrics and Gynecology Hospital on issuing the internal document "Regulations on nurses' activities". p. 5961. (In Vietnamese)

2. Ministry of health (2014), Promulgating the code of conduct for officials, civil servants 
and employees working at healthcare establishments, Circular 07/2014/TT-BYT dated 25/2/2014 . (In Vietnamese)

3. Pham Thi Xuyen (2015), The routine bedside assessment of nurses at Ha Dong General Hospital, 2015, Master thesis in hospital management, Ha Noi University of Public Health. (In Vietnamese)

4. Do Manh Hung (2014), The awareness, practice of ethical codes among nurses at National Children's Hospital and results of applying some interventions, Dissertation in Public Health Thai Binh University of Medicine and Pharmacy. $p$. 4-30. (In Vietnamese)

5. Ministry of health (2015), Renovating the style and attitude of healthcare providers towards patient satisfaction, Decision No. 2151/QD-BYT dated June 4, 2015. (In Vietnamese)

6. Hoang Tien Thang (2010), Effects of nurses' communication skills on inpatient satisfaction at Son Tay General Hospital, the VII National Pediatric Nursing Scientific Conference. p. 42-47. (In Vietnamese)

7. Ha Thi Kim Phuong (2007), The effectiveness of the educational program on communication skills among Nurses - Technicians in Nam Dinh Provincial Psychiatric Hospital, 3rd National Nursing Scientific Conference. p. 40-47. (In Vietnamese) 